\title{
Erratum
}

\section{To the article "Initial-Value Technique for Self-Adjoint Singular Perturbation Boundary Value Problems" by H. K. Mishra, M. Kumar, and P. Singh, Vol. 20, No. 2, pp. 207-217, April-June, 2009}

During printing, two references from the reference list of the final revised paper were omitted. Because of this, the entire order of the references has been changed. The changes are as follows:

\section{On page 207}

In line 17, reference [9] should be replaced by reference [11].

In line 18, reference [11] should be replaced by reference [13].

In line 19, references $[7,8]$ should be replaced by references $[9,10]$.

In line 20, reference [6] should be replaced by reference [8].

In line 23, reference [12] should be replaced by reference [14].

In line 24, reference [10] should be replaced by reference [12].

In line 28, "In order to solve the singular perturbation problem, first we reduce Eq. (1) to its normal form and then the..." should be replaced by "In order to solve the singular perturbation problem, first we reduce Eq. (1) to its normal form $[4,5]$ and then the..."

\section{On page 210}

In line 9 , references $[4,5]$ should be replaced by references $[6,7]$.

\section{On page 211}

In line 16, reference [7] should be replaced by reference [9].

\section{On page 213}

In line 18, reference [13] should be replaced by reference [15].

\section{On page 217}

The correct order of references is as follows:

1. I. P. Boglaev, "A variational difference scheme for boundary value problems with a small parameter in the highest derivative," USSR, Comput. Math. Math. Phys., 21, No. 4, 71-81 (1981).

2. E. P. Doolan, J. J. H. Miller, and W. H. A. Schilders, Uniform Numerical Methods for Problems with Initial and Boundary Layers, Boole Press, Dublin (1980).

3. M. G. Gasparo and M. Macconi, "Initial-value methods for second-order singularly perturbed boundary value problems," J. Optim. Theory Appl., 66, 197-210 (1990). 
4. M. K. Kadalbajoo and V. K. Aggarwal, "Fitted mesh $B$-spline collocation method for solving self-adjoint singularly perturbed boundary value problems," Appl. Math. Computation, 161, 973-987 (2005).

5. M. K. Kadalbajoo and D. Kumar, "Geometric mesh FDM for self-adjoint singular perturbation boundary value problems," Appl. Math. Computation, 190, 1646-1656 (2007).

6. M. Kumar, P. Singh, and H. K. Mishra, "An initial-value technique for singularly perturbed boundary value problems via cubic spline,” Int. J. Comput. Meth. Eng. Sci. Mech., 6, 1-9 (2007).

7. M. Kumar, P. Singh, and H. K. Mishra, "Numerical treatment of singularly perturbed two-point boundary value problems using initial value method," Communicated.

8. J. J. H. Miller, "On the convergence uniformly in $\varepsilon$ of difference schemes for a two-point boundary singular perturbation problem," in: Numerical Analysis of Singular Perturbation Problems, Academic Press, New York, (1979), pp. 467-474.

9. K. Niijima, "On a three-point difference scheme for a singular perturbation problem without a first derivative term. II," Mem. Numer. Math., 7, 11-27 (1980).

10. K. Niijima, "On a three-point difference scheme for a singular perturbation problem without a first derivative term. I," Mem. Numer. Math., 7, 1-10 (1980).

11. M. H. Potter and H. F. Weinberger, Maximum Principles in Differential Equations, Prentice-Hall, Englewood Cliffs, NJ (1967).

12. M. Sakai and R. A. Usmani, “On exponential splines,” J. Approxim. Theory, 47, 122-131 (1986).

13. A. H. Schatz and L. B. Wahlbin, "On the finite element method for singularly perturbed reaction diffusion problems in two and one dimension," Math. Comput., 40, 47-89 (1983).

14. K. Surla and V. Jerkovic, "Some possibilities of applying spline collocations to singular perturbation problems," Numer. Meth. Approxim. Theory, Vol. II, Novisad, 19-25 (1985).

15. V. Vukoslavcevic and K. Surla, "Finite element method for solving self-adjoint singularly perturbed boundary value problems," Math. Montisnigri, VII, 69-86 (1996). 